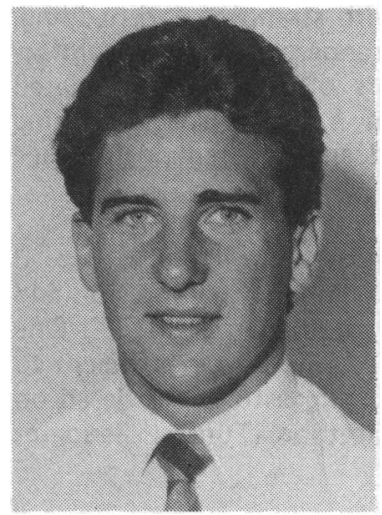

R. Northcote

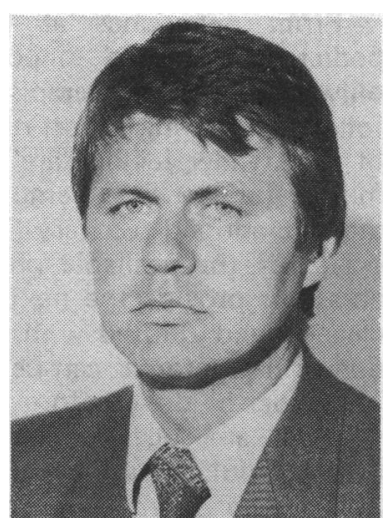

D. Ballantyne

\title{
REDUCING THE PREVALENCE OF EXERCISE RELATED CARDIAC DEATH
}

\author{
R. J. NORTHCOTE, MRCP and D. BALLANTYNE, MD, FRCP (Glasg.)
}

Department of Medical Cardiology, The Victoria Infirmary, Glasgow, Scotland

\section{INTRODUCTION}

Non-traumatic sudden death during or immediately following strenuous sporting activity is an event of which most sportsmen are aware. The subject has been the concern of sportsmen, sports governing bodies and the medical profession, and has often excited alarmist media reports.

Although there appears to be a statistically small increased risk of sudden death during strenuous exercise (Opie, 1975; Thompson et al, 1982), there remains an appreciable mortality (Northcote and Ballantyne, 1983, 1984). The majority of sudden deaths are attributed to cardiovascular disease, particularly coronary heart disease (CHD) and although a wide age range is affected, most subjects are over the age of 35 years (Northcote and Ballantyne, 1983).

It is the intention of this article to examine ways in which the prevalence of sudden cardiac death in sport can be reduced.

\section{DEMOGRAPHIC DATA}

At present, we are aware of 151 cases of sudden death which have occurred in association with strenuous sport and have been documented in the medical literature

Address for correspondence:

Dr. Robin J. Northcote,

Department of Medical Cardiology,

The Victoria Infirmary,

Glasgow G42 9TY
(Northcote and Ballantyne, 1984). Only six non-cardiac causes of death are recorded, four being attributed to intracranial haemormage, one to heat stroke, and one to an acute gastro-intestinal haemorrhage. Of the cardiac causes, CHD accounted for 110 cases, followed by structural cardiovascular abnormalities such as hypertrophic obstructive cardiomyopathy (HOCM), coronary artery anomalies and valvular heart disease. A surprisingly small number (3) are attributed to myocarditis. Most of the deaths occurred in association with running, field sports and squash. The subjects ranged in age from 16-66 years, but were mostly over the age of 35 years (mean $=\mathbf{4 0} \pm 9.1$ years). Thirty-eight per cent suffered prodromal symptoms or conditions and 52\% of those with CHD had documented risk factors for CHD. The prodromal symptoms included chest pain, dyspnoea, fatigue and gastrointestinal upsets. The most prevalent CHD risk factor was smoking.

In summary, it would appear from this data that most sudden deaths are atrributed to cardiac disease, most frequently CHD, and a proportion of individuals may be at greater risk because of the presence of pre-morbid conditions and $\mathrm{CHD}$ risk factors.

\section{Cardiovascular Effects of Strenuous Sport}

Sudden and excessive exercise is believed to be more likely to precipitate "heart attacks" in the unfit (Shephard, 1974). In addition, competitive sports may be more likely to precipitate sudden death than exercise training alone (Opie, 1975). It is probable, also, that aggressive individuals taking part in highly competitive sports are at greater risk. 
A number of workers have reported the heart rate (HR) responses to various sports. In squash we have recently confirmed HR responses of $80 \%$ of the predicted maximum heart rate (PMHR), sustained for up to 40 minutes in healthy volunteers (Northcote et al, 1983). Similar studies in tennis have reported HR response of $60-70 \%$ of PMHR for periods of rally play only (Misner et al, 1980). Heart rate has been shown not to rise above $100 \mathrm{bpm}$ in golf, bowls or cricket (Kozar and Himsicher, 1963).

\section{Cardiac Arrhythmias}

Cardiac arhythmias, including ventricular tachycardia, have been demonstrated in a group of healthy male individuals during squash (Northcote et al, 1983). One can assume, that such arrhythmias would be more likely in the presence of CHD. Apart from myocardial ischaemia, a number of reasons exist which may explain this phenomenon during or immediately after exercise.

Serum catecholamines rise during strenuous exercise and may result in myocardial ischaemia and arrhythmias in the presence of CHD (Raab et al, 1962). In the immediate post-exercise period, serum concentrations of catecholamines and free fatty acids are known to be elevated (Dimsdale et al, 1984; Johnson et al, 1969). Both of these changes may be responsible for cardiac arrhythmias at this time (Northcote et al, 1983; Gooch and McConnel, 1970). Other biochemical changes such as exercise induced hyperkalaemia, may also contribute to the generation of arrhythmias (Lim et al, 1981). Likewise, environmental influences such as humidity and high temperature, are known to elevate heart rate and increase cardiac ectopic activity (Taggart et al, 1972). Smoking is capable of stimulating both catecholamine release and an increase in free fatty acids in the serum (FFA's) (Ball and Turner, 1974; Kershbaum et al, 1961).

\section{Heat Stroke}

Heat stroke, noted particularly in marathon running (Wyndham and Strydom, 1969), may result in haemoconcentration, which could make thrombus formation and subsequent coronary artery occlusion more likely. It has also been shown to cause patchy, subendocardial necrosis (O'Donnel and Clowes, 1972).

The potentially hazardous effects of strenuous exercise outlined above are probably more harmful in the presence of $\mathrm{CHD}$ or other cardiovascular abnormality. It is likely, that in the normal heart, these influences are benign.

\section{PREVENTION}

\section{Recognising the Problem}

Study into the phenomena of sudden death during vigorous exertion, is hindered by inadequate registration and investigation of each case. At present, a death is registered without information of the activity of the deceased prior to death. Thus, the frequency of death during exercise is not known. There is a need for greater recognition of this problem in view of the growth in the number of reported deaths and increasing age of participants. Sports governing bodies can assist by attempting to document the extent and nature of sudden death in their own sport. The Squash Rackets Association (SRA) is to be commended for its efforts in this way. They have gone as far as circulating some sensible suggestions to prospective players in an effort to reduce any complications occurring when playing squash.

\section{Which Sport?}

It is perhaps unfortunate, that squash has been subject to much media coverage because of the prevalence of sudden death. This may be a reflection of the individuals engaged in the sport. The SRA themselves, estimate that there may be 165,000 players over 45 years of age playing in the UK. As it is such a physically demanding sport, it may be wiser for individuals in the coronary prone age group to consider more gentle forms of exercise if taking up sport for the first time after some years of inactivity. The present boom in marathon running is also potentially hazardous to the coronary prone or those with undetected, overt, cardiovascular disease. Only a few years ago, we would have questioned the sanity of recommending a 26 mile run to a 50 year old, but now this activity is encouraged! There is no evidence that such endeavours are more beneficial to the cardiovascular system, than other, more gentle forms of exercise. Why has jogging a few miles a few times a week become "unfashionable"? We would recommend that individuals should be encouraged to exercise, but to participate in sports which are suited to their age, physical ability and general health. Walking, jogging, swimming and cycling would be suitable in this respect.

\section{Education}

There is a requirement for more adequate education and supervision of the embryo sportsman. All sportsmen should be aware of the small risks attached to vigorous exercise, and should be able to recognise warning symptoms. Aggressive, competitive sportsmen have been noted to deny prodromal symptoms (Opie, 1975; Northcote et al, 1984). Individuals should be encouraged to refrain from strenuous exercise if such symptoms occur. It has been suggested that individuals should not exercise when suffering from an upper respiratory tract infection or other pyrexial illness, as this can be accompanied by a potentially lethal subclinical myocarditis (Kocnar and Rous, 1973). Although we have not been able to implicate myocarditis as an important cause of sudden death in sportsmen, we agree that vigorous exercise should be discouraged at this time. The medical profession and those concerned with the supervision of sportsmen should be aware of the consequences of such 
prodromal symptoms and conditions. In a recent study (Northcote et al, 1984), of 30 sudden deaths in association with squash, we found that one third of the individuals had hypertension documented on two or more occasions, but this had been treated in only one subject. Three subjects had hyperlipidaemia, three had angina or previous myocardial infarction (MI) and one subject was known to have suffered a myocardial infarct 10 years previously and also had aortic regurgitation, requiring regular review at a cardiology clinic. This subject had been told by his doctors that there was no harm in playing squash!

\section{Pre-participation Medical Screening}

Individuals such as those outlined above may benefit from medical screening which would detect overt cardiovascular disease and would indicate a relatively increased risk. However, having been advised of this increased risk, it is of course the individual's decision whether he persists in playing a particular sport.

The practicality of medical screening has been questioned. However, often a simple interview and clinical examination would suffice. This would allow detection of CHD risk factors, and overt, potentially lethal cardiovascular disease. If a subject was found to have one or more CHD risk factors or was symptomatic, we would advocate screening using exercise electrocardiography. This policy has also been suggested elsewhere (Chung, 1980; Levy, 1981; Nye, 1983).

The value of exercise electrocardiography in this respect is not solely related to the detection of $\mathrm{CHD}$. It can be a useful investigation for predicting future coronary events. There is good evidence that it does so (Table 1). Bruce and McDonough (1969) studied 221 asymptomatic men and found that those with an abnormal appearance on the exercise electrocardiogram had a relative risk of subsequent CHD, 13.6 times greater than normal over the subsequent five years. Other workers have reported similar results ranging from a relative risk of 10-20 (Aronow, 1973; Forelicher et al, 1974 Cumming et al, 1975). We believe that the evidence of the exercise test result, when added to the other risk factors assessed, would enable one to provide better advice to the subject contemplating strenuous sporting activity. In the present state of knowledge, however, it would not be justifiable to proceed from a positive exercise test result in an asymptomatic subject to either thallium scintigraphy or coronary angiography.

We appreciate the potential cost of such a programme but feel this could be minimised by screening the population at greatest risk, i.e. males $>\mathbf{3 5}$ years. Facilities for this could perhaps be made available on a payment basis within the NHS or could be provided by individual sports centres.

\section{Changes in individual sports}

Certain sports could be made safer by alterations in their rules. In boxing, title fights are now conducted over 12 rounds instead of 15, and Olympic boxers now require to wear "head guards". Possibly by improving the environment of some sports, a reduction in mortality may occur. Improved ventilation and temperature control on squash courts may be beneficial. Although it would seem commercially unviable at the present alterations in court design may be desirable. Various changes have recently been suggested such as removing the back wall, or making the court bigger - both of these measures would reduce the length of rallies and perhaps place more emphasis on racquet head skill, rather than physical effort.

\section{Useful Precautions}

Adequate warming-up and warming-down should be encouraged, this may reduce the number of dysrhythmic deaths. Likewise the discouragement of smoking and

\section{TABLE I}

Follow-up studies using maximal treadmill test to screen asymptomatic men for latent coronary heart disease.

\begin{tabular}{|c|c|c|c|c|c|}
\hline Main investigator & $\begin{array}{c}\text { Years } \\
\text { followed-up }\end{array}$ & $\begin{array}{l}\text { Exercise } \\
\text { test used }\end{array}$ & $\begin{array}{l}\text { ST segment } \\
\text { response }\end{array}$ & $\begin{array}{c}\text { No. }(\%) \text { of } \\
\text { total } \\
\text { population }\end{array}$ & $\begin{array}{c}\text { No. developing } \\
\text { CHD }(\%) \text { of } \\
\text { ECG response } \\
\text { group }\end{array}$ \\
\hline $\begin{array}{l}\text { Bruce and McDonough } \\
\text { ( } 221 \text { subjects) }\end{array}$ & 5 & $\begin{array}{l}\text { Bruce test } \\
\text { (CB) }\end{array}$ & $\begin{array}{l}\text { Abnormal } \\
\text { Normal }\end{array}$ & $\begin{array}{r}22(10) \\
199(90)\end{array}$ & $\begin{array}{l}3(13.6) \\
2(1)\end{array}$ \\
\hline Aronow (100 subjects) & 2.5 & $\begin{array}{l}\text { Bruce test } \\
\text { (V) }\end{array}$ & $\begin{array}{l}\text { Abnormal } \\
\text { Normal }\end{array}$ & $\begin{array}{l}13(13) \\
87(87)\end{array}$ & $\begin{array}{l}3(23) \\
1(1.1)\end{array}$ \\
\hline $\begin{array}{l}\text { Froelicher et al } \\
\text { (1390 subjects) }\end{array}$ & 6.3 & $\begin{array}{l}\text { Balke test } \\
\text { (CC) }\end{array}$ & $\begin{array}{l}\text { Abnormal } \\
\text { Normal }\end{array}$ & $\begin{array}{r}140(10) \\
1250(90)\end{array}$ & $\begin{array}{l}28(20) \\
18(1.4)\end{array}$ \\
\hline
\end{tabular}


avoidance of a hot bath or shower may reduce the harmful effects of increased levels of catecholamines, free fatty acids and potassium after exercise. Because of the risk of hyperpyrexia and heat stroke, vigorous activity in extreme heat should be avoided. The Boston Marathon in 1973, in which one runner died of a myocardial infarct was run when the environmental temperature was between $30^{\circ}-35^{\circ} \mathrm{C}$ (Sheehan, 1976). Fluid and electrolyte loss should be compensated, particularly during endurance events such as marathon running. Although feeding stations are available at most marathon events, not all runners utilise this service adequately. Hypothermia following cessation of activity, particularly in marathon runners, should be avoided by preventing heat loss. However, the practice of supplying aluminium foil "space blankets" to finishing competitors is an expensive and ineffective way to do this. It may be better for competitors to have their tracksuits made available at the finishing point.

\section{CONCLUSIONS}

Many may take the view that the preventive measures above are unnecessary because of the low statistical risk of sudden death in sport. However, the extent of the problem is probably grossly underestimated. We do not know the prevalence of non-fatal coronary events during exercise, and are dependent on media reports for information on sudden deaths. It has been estimated, that in squash alone, 27 deaths occur per annum in the UK (Fowler, 1980). If this is true then there are likely to be a considerable number of deaths in other sports, all amounting to an appreciable mortality. The suggestions expressed in this paper may help reduce the occurrence of sudden cardiac death in sport.

\section{REFERENCES}

Aronow, W. S., 1973 "Thirty-month follow-up of maximal treadmill stress test and double master's test in normal subjects". Circulation 47: $287-290$.

Ball, K. and Turner, R., 1974 "Smoking and the heart. The basis for action". Lancet 2: 822.

Bruce, R. A. and McDonough, J. R., 1969 "Stress testing in screening for cardiovascular disease". Bull.N.Y.Acad.Med.: $1288-1305$.

Chung, E. K., 1980 "Exercise ECG testing: is it indicated for asymptomatic individuals before engaging in any exercise program?" Arch.Intern.Med. 140: 895-896.

Cumming, G. R., Samm, J. and Borysyk, L. et al, 1975 "Electrocardiographic changes during exercise in asymptomatic men: 3 year follow-up". Can.Med.Assoc.J. 112: 578-581.

Dimsdale, J. E., Hartley, H., Guiney, T., Ruskin, J. N. and Greenblatt, D., 1984 “Postexercise period: plasma catecholamines and exercise". JAMÁ 251: 630-632.

Fowler, A. W., 1980 “Cause of death on squash courts.". On Call 14: 7.

Froelicher, V. F., Thomas, M., Pillor, C. et al, 1974 "An epidemiological study of asymptomatic men screened with exercise testing for latent coronary heart disease". Am.J.Cardiol. 34: 770-776.

Gooch, A. S. and McConnel, D., 1970 "Analysis of transient arrhythmias and conduction disturbances occurring during submaximal treadmill exercise testing". Proc. Cardiovasc.Dis. 13: 293-307.

Johnson, R. H., Walton, J. L., Krebs, H. A. and Williamson, D. M., 1969 "Metabolic fuels during and after severe exercise in athletes and non-athletes". Lancet 2: 452-455.

Kershbaum, A., Bellet, S., Dickstein, E. R. and Feinberg, L. J., 1969 "Effect of cigarette smoking and nicotine on serum free fatty acids, based on a study in the human subject and the experimental animal". Circ. Res. 9: 631-638.

Kocnar, K. and Rous, J., 1973 "Preventive approach to sudden death at sports performance". Brit.J.Sports Med. 7: 166-167.

Kozar, A. J. and Himsicher, P. A., 1973 "A study of telemetred heart rate during sports participation". J.Sports Med.Phys.Fitness 3: 1.5 .

Levy, R. I., 1981 "Exercise and your heart" (NIH publication 81-1677). Washington: US Department of Health and Human Sciences.

Lim, M., Linton, R. A. F. and Band, D. M., 1982 "Joggers blockade". BMJ 284: 826.

Misner, J. E., Boileau, R. A., Courvoisier, D., Slaughter, M. H. and Bloomfield, D. K., 1980 "Cardiovascular stress associated with the recreational tennis play of middle aged males". Amer.Corr. Ther.Jnl. 34: 4-8.

Northcote, R. J., MacFarlane, P. and Ballantyne, D., 1983 "Ambulatory electrocardiography in squash players. Brit.Heart J. $50: 372-377$.

Northcote, R. J. and Ballantyne, D., 1983 "Sudden cardiac death in sport". BMJ 287: 1357-1359.

Northcote, R. J., Evans, A. D. B. and Ballantyne, D., 1984 "Sudden deạth in squash players". Lancet 1: 148-151. 
Northcote, R. J. and Ballantyne, D., 1984 "Sudden death in sport". Leading article. Sports Medicine 1: $181-186$.

Nye, E. R., 1983 "Exercise and the middle-aged patient". National Heart Foundation of New Zealand. Technical Report Series. Report No. 37.

O'Donnel, T. F. Jr. and Clowes, G. M. A. Jr., 1972 "The circulatory abnormalities of heart stroke". N.Engl.J.Med. 287: $734-737$.

Opie, L. H., 1975 "Sudden death in sport". Lancet 1: 263-266.

Raab, W., Van Lith, P., Lepeschin, E. and Herrlich, H. C., 1962 "Catecholamine induced myocardial hypoxia in the presence of impaired coronary dilatability independent of external cardiac work". Am.J.Cardiol. 9: 455-470.

Sheehan, G., 1976 "Marathon racing and myocardial infarction". Annals of Intern.Med. 85: 392.

Shephard, R. J., 1974 "Sudden death - a significant hazard of exercise". Brit.J.Sports Med. 8: 101.

Taggart, P., Parkinson, P. and Carruthers, M., 1972 "Cardiac responses to thermal, physical and emotional stress". BMJ 3: 71-76.

Thompson, P. D., Funk, E., Carleton, R. A. and Sturner, W. Q., 1982 "Incidence of death during jogging in Rhode Island from 1975 through 1980". JAMA 247: 2535-2538.

Wynctham, C. A. and Strydom, N. B., 1969 "The danger of an inadequate water intake during marathon running". S.Afr.Med.JnI. 43: 893-896.

\section{EDINBURGH POST-GRADUATE BOARD FOR MEDICINE}

(The University of Edinburgh, The Royal College of Physicians of Edinburgh, The Royal College of Surgeons of Edinburgh)

Held in Lister Institute, Roxburgh Place, Edinburgh

Registration from 9 a.m. (2 sessions: $£ 20$ : Section 63)

SPORTS MEDICINE

1st February, 1985

Run by Drs. Donald MacLeod, FRCS and Elizabeth McSwan, MBChB, this one day course will deal with varied aspects of sports medicine. It is intended for all doctors involved in the medical care of those participating in sport.

\section{MARATHON MEDICINE MEETING \\ 20th April, 1985 (Saturday before London Marathon) \\ Held in The Royal Festival Hall}

Details from Dr. Dan Tunstall Pedoe, Cardiac Dept., St. Bartholomew's Hospital, London EC1A 2BE

\section{INTERNATIONAL SYMPOSIUM ON SPORTS CARDIOLOGY \\ 10th-12th May, 1985 \\ Knokke}

Details from Bekaert I, Algemeen Ziekenhuis Sint-Jozef, Steenweg op Merksplas 44, 2300 Turnhout, Belgium Tel. 014/41.04.51 ext. 3514 